\title{
Modelling the Effects of Parking Charge and Supply Policy Using System Dynamics Method
}

\author{
Zhenyu Mei, ${ }^{1}$ Qifeng Lou, ${ }^{1}$ Wei Zhang, ${ }^{1}$ Lihui Zhang, ${ }^{1}$ and Fei Shi ${ }^{2}$ \\ ${ }^{1}$ Department of Civil Engineering, Zhejiang University, Hangzhou 310058, China \\ ${ }^{2}$ Department of Urban Planning, Nanjing University, Nanjing 210093, China \\ Correspondence should be addressed to Zhenyu Mei; meizhenyu@zju.edu.cn
}

Received 5 January 2017; Revised 23 March 2017; Accepted 10 May 2017; Published 13 June 2017

Academic Editor: Angel Ibeas

Copyright (c) 2017 Zhenyu Mei et al. This is an open access article distributed under the Creative Commons Attribution License, which permits unrestricted use, distribution, and reproduction in any medium, provided the original work is properly cited.

\begin{abstract}
Reasonable parking charge and supply policy are essential for the regular operation of the traffic in city center. This paper develops an evaluation model for parking policies using system dynamics. A quantitative study is conducted to examine the effects of parking charge and supply policy on traffic speed. The model, which is composed of three interrelated subsystems, first summarizes the travel cost of each travel mode and then calibrates the travel choice model through the travel mode subsystem. Finally, the subsystem that evaluates the state of traffic forecasts future car speed based on bureau of public roads (BPR) function and generates new travel cost until the entire model reaches a steady state. The accuracy of the model is verified in Hangzhou Wulin business district. The related error of predicted speed is only $2.2 \%$. The results indicate that the regular pattern of traffic speed and parking charge can be illustrated using the proposed model based on system dynamics, and the model infers that reducing the parking supply in core area will increase its congestion level and, under certain parking supply conditions, there exists an interval of possible pricing at which the service reaches a level that is fairly stable.
\end{abstract}

\section{Introduction}

Parking policy is a direct and effective approach in traffic demand management [1]. It affects parking demand and travel state and helps ease parking difficulty and traffic in the central area of a city. However, predicting the actual benefits of the implementation of this policy is challenging. Thus, we should determine whether the new parking policy is more appropriate and effective than the currently implemented policy. Therefore, this study aims to analyze the influence of parking charge and supply policy on travel mode choice and road network state and to establish the relationship among parking policy, travel mode choice, and road network state.

Parking policy is implemented in two mechanisms: by changing the level or structure of parking charges and by altering the supply of parking spaces [2]. Reasonable parking charge and supply help alleviate parking and driving difficulties in the city center. The structure of urban traffic is a consequence of the cost of the different travel choices. Strict parking policy with high charge and low supply can reduce the volume of cars in the central area on one hand, but the parking search time will be prolonged for its low parking supply. This condition results in partial traffic congestion and entails high charges. On the contrary, flexible policy with low charge and high supply can increase the volume of cars that enter the central area and may also increase traffic congestion.

Parking policy has been extensively investigated in terms of its influence on various aspects and numerous advantages. The effects of parking policy not only on parking demand but also on the whole traffic system have also been widely explored.

Parking charge and supply policy are considered as two essential factors that affect parking behavior. Different parking policies, trip structure, public transit, traffic facilities, and other factors can influence parking demand distribution $[2,3]$. As the two main forms of parking policy, parking charge and supply policy significantly affect parking choice [4-6].

The effects of parking charge and supply policy on traffic congestion have also been evaluated. Parking charge and 
supply are considered the second most effective tool to alleviate traffic congestion, and they are easier to be carried out compared with congestion charging $[7,8]$. Arnott and Rowse [9] and Cutter and Franco [10], respectively, established the relationship model of parking and traffic congestion. Cruising time is also crucial when parking management and traffic condition are optimized on the basis of parking policy $[11,12]$ because cruising time is a relevant factor of traffic congestion [13]. These models reveal the relationship between parking policy and traffic congestion in different aspects, but road network state should be further evaluated on the basis of parking policy.

Traditional four-stage modes or dynamic microsimulation models are costly and unsuitable for this study because parking policy implementation is a complicated process. Conversely, system dynamics $[14,15]$ is an approach to understand the nonlinear behavior of complex systems, and it is employed in public and private sectors for policy analysis and design. With its special advantages, a model with system dynamics is established to determine the complexity of parking policy and accept its dynamic characteristics. Bernardino and Hoofd [16] developed a model by applying system dynamics to assess the effectiveness of parking policy in predicting traffic congestion and speed, but this model has failed to quantify travel cost. The types of policies are mainly associated with parking price, whereas parking supply is rarely considered. Therefore, the present study explores the actual state of traffic in terms of the effects of parking charge and supply by using a discrete choice model. Our results will provide a scientific basis for traffic management.

Different parking policies directly influence travel cost, which possibly affects the choice of travel mode and travel structure. Also, travel mode choice contributes to the condition of road network state, which also influences travel cost accordingly. Therefore, travel cost is related to travel mode choice and road network state. This study aims to evaluate the influence of parking policy on road network by identifying the relationship among the three factors.

Travel cost is a decisive factor of trip decision and directly influences the choice of travel behavior. Since the 1970s, travel costs have been quantified in monetary terms [17]. On a microperspective, studies on travel cost aim to evaluate the traveler's choice of travel mode. Travel time and travel cost are considered, and travel cost is calculated by using travel time values based on random utility theory in a travel mode choice model [18]. In addition to studies on the travel cost of one trip, research on travel cost quantification based on a trip chain has been performed [19].

Since the early 1960s, factors influencing the changes in modes [2], especially between car and public transport modes, have been investigated. The main models include discriminant model [20], probit model [21], and logit model $[5,22]$. The effects of policy or other factors on the choice of travel behavior have also been analyzed on the basis of a logit model.

Travel mode directly affects the traffic flow on a road network and the state of the road network [23]. Changes in the travel mode choice can effectively alleviate regional traffic, and parking policy is an effective method to alter the travel mode choice [24].

Therefore, this paper proposes a method to estimate the travel mode choice based on travel cost as influenced by parking policy. The travel cost of various travel modes is selected as basic variables, and travel mode choice is subjected to multivariate logit model analysis. A prediction method is also established to estimate the average speed of road network based on the current network speed, which greatly minimizes the difficulty in investigating the condition of network model calibration and evaluation. The proposed method can determine the dynamic travel cost, identify the travel choice for network speed prediction, and provide a scientific basis for parking demand management.

The major contributions of this study are described as follows:

(1) An evaluation model of the combined effects of parking charge and supply policy is proposed. The model contains three subsystems to calculate travel cost, make a travel choice based on travel mode, and evaluate the traffic state under parking policy.

(2) The travel cost of each travel mode is chosen as the basic variable because travel cost is the basis for travel choice analysis, and the essential difference among various carriers is travel cost that includes direct and indirect costs.

(3) This paper presents a method to predict the future road network speed after the new parking policy is implemented on the basis of the current traffic state. The model can continuously determine dynamic variables, such as travel cost and travel mode distribution, to predict road network speed, which provides a scientific basis for parking demand management.

This paper is organized as follows. Section 2 describes the structure of the three subsystems in the evaluation model in detail. Section 3 verifies and discusses the effectiveness of the proposed method based on future parking policy simulation. Section 4 presents the conclusions.

\section{Model Development}

2.1. Parking Charge and Supply Policy Evaluation Model. This model aims to study the state of traffic under the influence of parking charge and supply policy in a certain district. Usually, alleviating traffic congestion in the city center, especially in the center business district (CBD), is the purpose of related policies. So, the center business district is chosen as the study area.

The effects on the traffic of the parking policy are complicated process, and the affected objects are potential parking lot users. The four-stage model is not suitable to analyze the effects of policy on the traffic system. But system dynamics make it possible to understand the complicated process. For its special advantages, a model using system dynamics that can capture the complexity of parking policy while accepting its dynamic characteristics is built in this paper. 


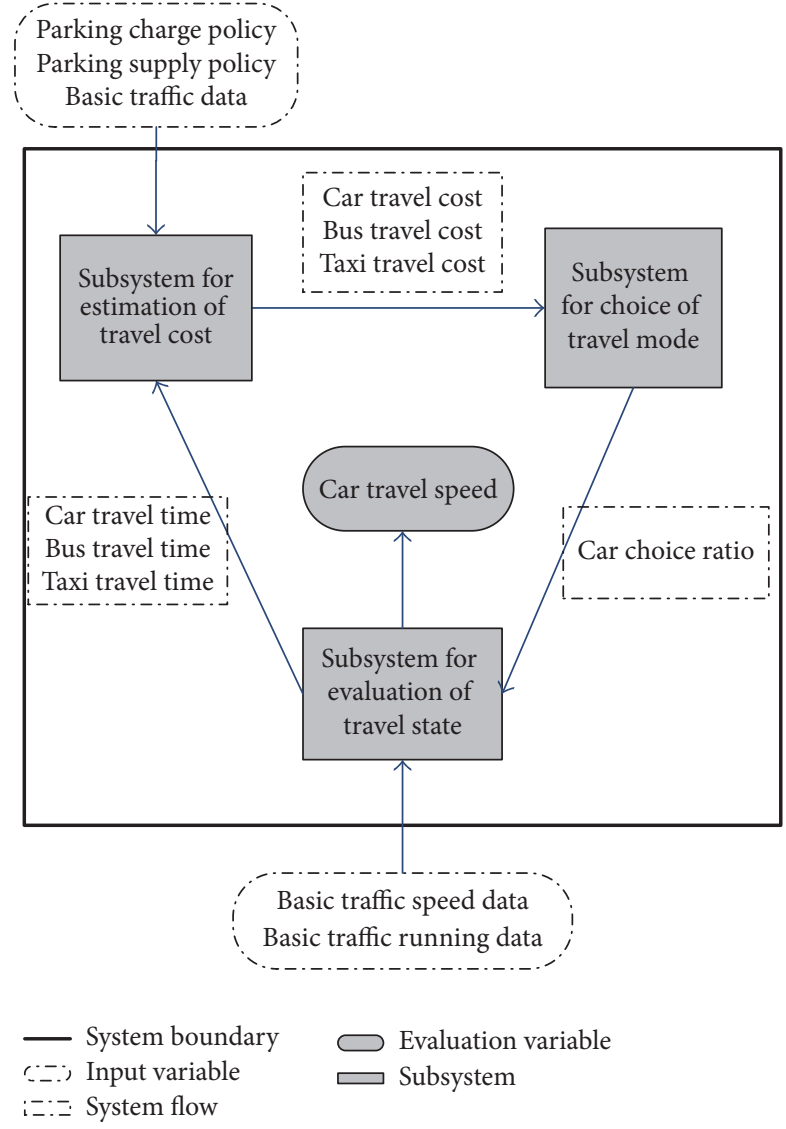

FIGURE 1: Evaluation model of the combined effects of parking charge and supply policy.

For the convenience of research, several assumptions are made in the evaluation model as follows:

(1) The total travel demand in the study area is fixed, but the choice of travel modes is flexible.

(2) There is no bus lane or rail transit in the study area; public transportation only contains bus transit.

(3) The travel speeds of cars and buses interact with each other and are treated as the same.

The model is composed of three subsystems, namely, subsystem for estimation of travel cost, subsystem for choice of travel mode, and subsystem for evaluation of traffic state. The structural diagram of evaluation model is shown in Figure 1.

The variables of the model, like the traffic speed, parking supply ratio, time value, and others, are chosen as the average value. According to the structural diagram of evaluation model in Figure 1, the variables in the model can be classified into input variables, flow variables, and output variables. The input variables include three parts. Firstly, parking policy variables such as parking charge and parking supply are necessary to evaluate the effects of parking policy. Secondly, three travel modes, which are car, bus, and taxi, are considered in the travel mode choice subsystem according to Figure 1. And to estimate the travel cost, fuel price, taxi fee, average time value, and some other variables connected to the cost need to be considered. Lastly, to evaluate the travel state, traffic characteristic variables such as free-flow speed and initial bus speed should be taken into consideration. The flow variables of the model include the travel cost of different travel modes, car's travel time, and congestion level. The output variable that measures the service level of traffic is the travel speed of cars.

A typical trip can be classified into two types, namely, commuting trip (going to work, school, or home) and extra trip (going to shops, entertainment centers, or restaurants). The parking place for a commuting trip is usually the parking lot annexed to the companies or villages. The parking fee for this kind of trip is free or paid monthly and is not significantly affected by policies. Therefore, the presented model focuses on extra parking behavior.

\subsection{Subsystems of the Model}

2.2.1. Subsystem for Estimation of Travel Cost. Travel cost is the basis of analysis in making travel choices. The subsystem for estimating travel cost aims to turn the indirect cost of each travel mode into money. This subsystem combines the travel cost of each travel mode with direct cost.

The fee for traffic instruments is only trip consumption that can be directly felt by travelers. The subsystem for estimating travel cost can provide a quantitative index that enables travelers to evaluate the quality of travel mode.

Direct cost is the direct money expenses on one trip, including the fee for traffic instrument, parking fee, and oil consumption. Indirect cost includes time cost, comfort cost, and time reliability cost. Time cost means the maximum return that a traveler can obtain from the time lost on one trip. Time reliability cost is the cost of time reserved by travelers because they cannot predict an accurate travel time on one trip. Comfort cost includes the cover of vehicles, the degree of congestion, and other factors that have a direct relationship with the current high vehicle ownership in large cities.

Residents can choose from several modes of travel, such as cars, buses, taxis, and subway, but this study does not calculate all kinds of travel cost in the model. Only four main types of vehicles are used: cars, taxis, nonmotor vehicles, and buses. Only cars, taxis, and buses are affected by the state of traffic. Traffic congestion increases these three travel choices and raises their travel cost, but it does not affect nonroad travel choices such as the subway. So, the travel cost subsystem calculates the travel cost of cars, taxis, and buses only. The diagram of estimating car travel cost subsystem is displayed in Figure 2.

In Figure 2, to calculate the car travel cost, several main parts, including parking cost, parking search time cost, travel time cost, fuel cost, and car reliability cost, are taken into consideration. Similarly, when it comes to bus travel cost, bus travel time cost, bus ticket, walking, and waiting time cost, bus reliability cost and bus congestion cost are considered. For taxi travel cost, taxi travel time cost, waiting time cost, taxi fee, and taxi reliability cost are considered. 


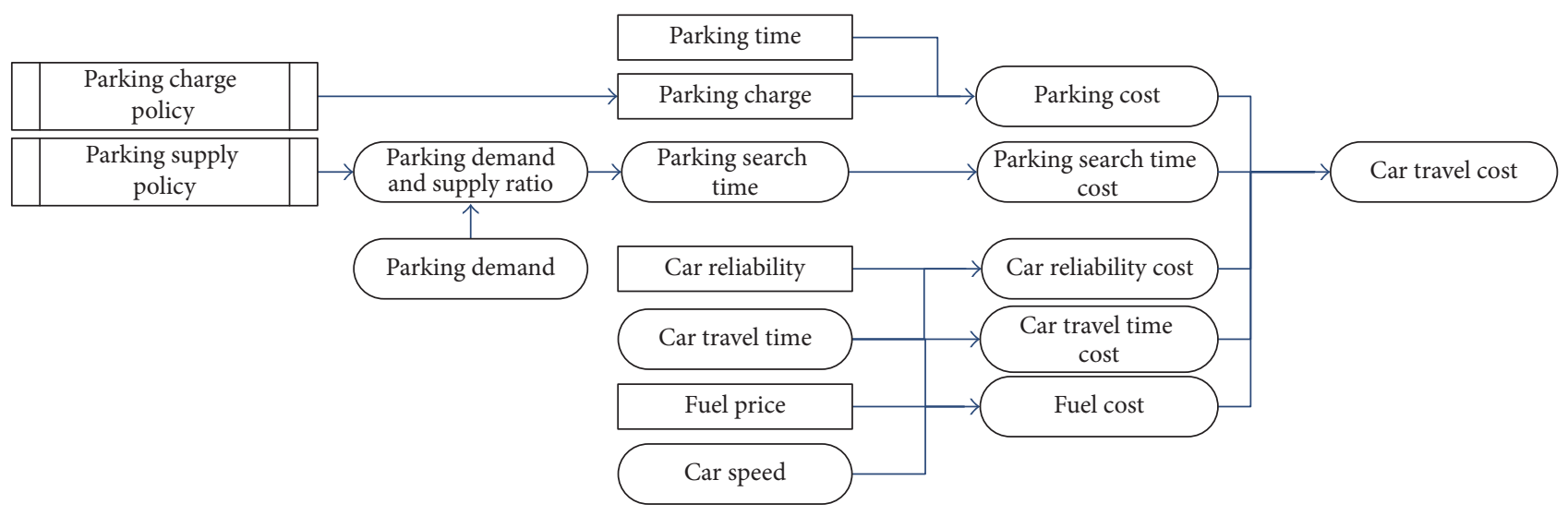

FIGURE 2: Subsystem for estimating car travel cost.

The main parameters of the subsystem that estimates time cost are described as follows.

(1) Time Value. According to the World Bank [25], the travel time value $p_{v}$ of adults in extra trip is 0.3 times the hourly wage. Parking search time, walking time, and waiting time value can be treated as 1.5 times the value of travel time. The rate of car load is denoted by $C_{f}$, travel time of road $a$ at moment $t$ is $t_{a}$, and the standard deviation of travel time is $\sigma$. Congestion cost $T_{\mathrm{cc}}$ [26] and reliability cost $T_{r}$ [19] are denoted as

$$
\begin{aligned}
& T_{\mathrm{cc}} \\
& = \begin{cases}0 & 0 \leq C_{f} \leq 0.8 \\
\sum_{a} t_{a} 0.55\left(C_{f}-0.8\right) e^{-0.74\left(C_{f}-0.8\right)^{2} p_{v}} & C_{f}>0.8,\end{cases} \\
& T_{r}=1.77 p_{v} \sigma .
\end{aligned}
$$

(2) Fuel Cost. If the car average speed is denoted by $v$, fuel price is $P_{f}$, and total time on one trip is $T$; then fuel cost $T_{f}$ [27] is

$$
\begin{gathered}
T_{f} \\
= \begin{cases}\left(5.143-0.077 v+0.001 v^{2}\right) \times P_{f} \times T & \text { normal } \\
\left(5.917-0.127 v+0.002 v^{2}\right) \times P_{f} \times T & \text { peak }\end{cases}
\end{gathered}
$$

2.2.2. Subsystem for Choice of Travel Mode. The function of the subsystem for travel mode choice is to calculate the ratio of car choice to the travel cost of each travel mode in an extra trip using the logit model.

Logit function is used to predict the travel choice distribution in the model. The logit model does not require a simulation method. This model is used widely in the predicting travel mode choice. The research objects of this

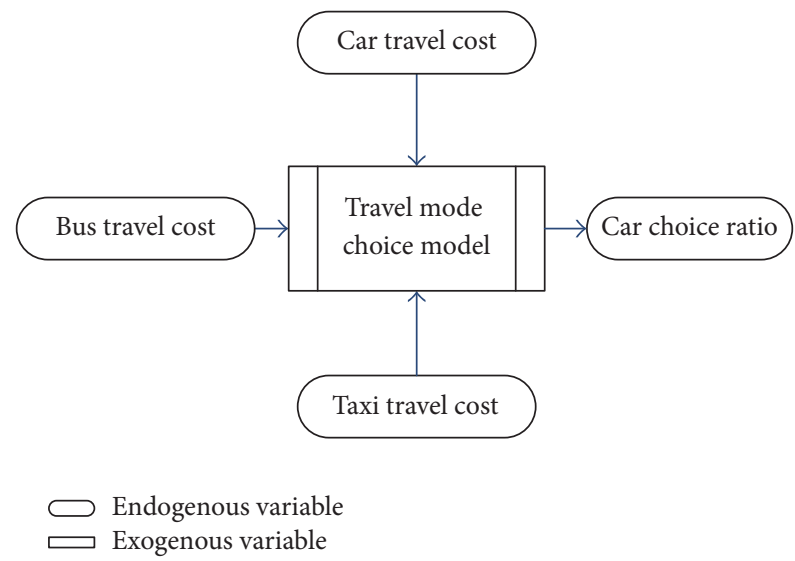

FIgURE 3: Subsystem for the choice of travel mode.

study are car, taxi, bus, and other travel modes. The diagram of this subsystem is displayed in Figure 3

We take residents who have travel demands in a district as a collective. The basis for the travel mode choice $i$ of each person in the collective is the maximum mode utility $U_{i}$. The factors that affect $U_{i}$ include parking price and bus service level. The influencing factors can be divided into travel cost factor $V_{i}$ and random factor $\varepsilon_{i}$. Utility function $U_{i}$ is

$$
U_{i}=V_{i}+\varepsilon_{i}
$$

The logit model assumes that random factor $\varepsilon_{i}$ obeys the Gumbel distribution. Thus, the probability of travel mode choice $i$ is

$$
P_{i}=\frac{e^{U_{i}}}{\sum_{j \in S} e^{U_{j}}} .
$$

The effects of travel costs on travelers are different considering the developing levels of different cities. Thus, the influence 


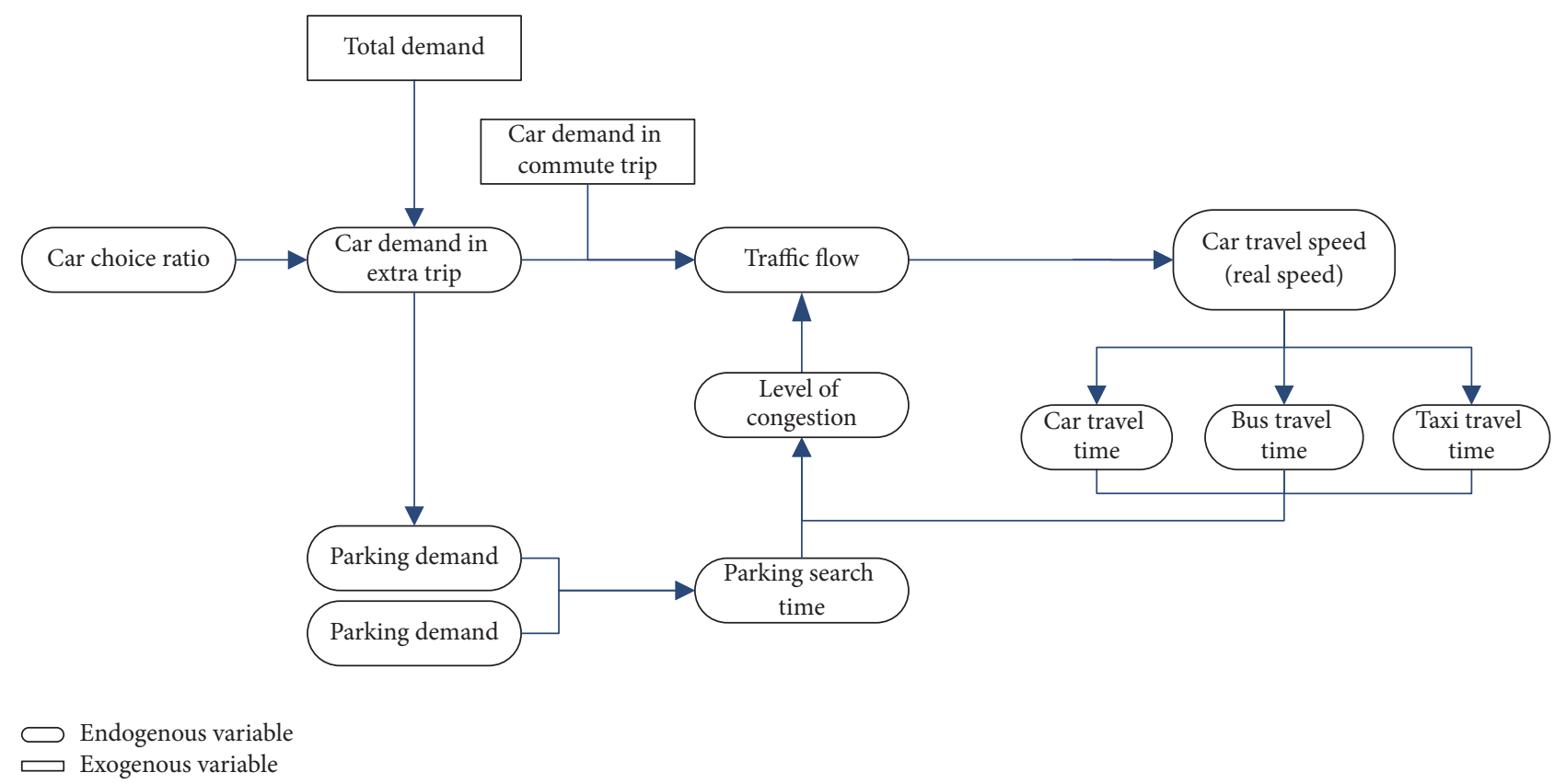

FIGURE 4: Subsystem for evaluating the state of traffic.

coefficient $\eta_{i}$ is the corresponding parameter for travel mode $i$, and $C_{i}$ represents the total travel cost of travel mode $i$. Then, the travel cost factor $V_{i}$ can be denoted as

$$
V_{i}=\eta_{i} C_{i}
$$

Car choice ratio in an extra trip after the new parking policy can be calculated according to the current travel mode distribution and the new parking policy.

2.2.3. Subsystem for Evaluation of Traffic State. The function of the subsystem for evaluating the state of traffic is to forecast a car's travel speed using the car choice ratio. The detailed process of evaluating traffic state subsystem is shown in Figure 4.

The main relationships in the subsystem for evaluating the state of traffic are as follows.

(1) Relationship between Car Choice Ratio and Car Travel Speed. Data on traffic demand and capacity of the road network of Hangzhou have no current records, and accurate values are difficult to obtain. Nevertheless, an existing realtime system can record the average travel speed in the Hangzhou road network, and the data are more complete. A series of unchanged data, such as total demand in commute trip and capacity of road network, can be reduced by comparing the state of traffic. Future car travel time after changes in charge policy can be predicted by the change in travel choice ratio and the current travel speed of car. Parking search time has been seen as an important part when analyzing the traffic congestion. In the next part, the effects of parking search time on traffic congestion are discussed and parking search time is taken into the model. The relationship between travel mode distribution and travel speed is illustrated in Figure 5.
This study focuses on the evaluation of parking charge policy for public parking lots. This policy mainly affects extra trips. The effect of the policy on commuting trips is small. Thus, only the changes in traffic demand for extra trips are considered in later calculations. The traffic demand of one commuting trip is considered constant.

The average speed of the Hangzhou Traffic Congestion Index System is selected as the measured speed in this article. Assuming that the current total number of cars in a region is $N$, the measured speed is $V$, the total length of road network in the region is $L$, and the average flow in a region can be written as

$$
\mathrm{Q}=\frac{N \times V}{L} \text {. }
$$

According to the model for road resistance function (BPR function) of the American Federal Highway Administration, the relation between traffic flow and average travel time can be written as

$$
\frac{1}{V}=\frac{1}{V_{0}}\left[1+\alpha\left(\frac{Q}{C}\right)^{\beta}\right],
$$

where $V_{0}$ is the free-flow speed, $C$ is the actual capacity in the region, and $\alpha$ and $\beta$ are the model parameters. According to the American Federal Highway Administration, $\alpha$ and $\beta$ are the parameters in BPR function and have default values of $\alpha=0.15$ and $\beta=4$.0. The ratio of the congestion degree between the current situation and the situation after the parking charge policy changes in a region can be written as follows:

$$
\frac{Q / C}{Q_{x} / C}=\frac{Q}{Q_{x}}=\sqrt[\beta]{\frac{V_{0} / V-1}{V_{0} / V_{x}-1}}=\frac{N \times V}{N_{x} \times V_{x}},
$$




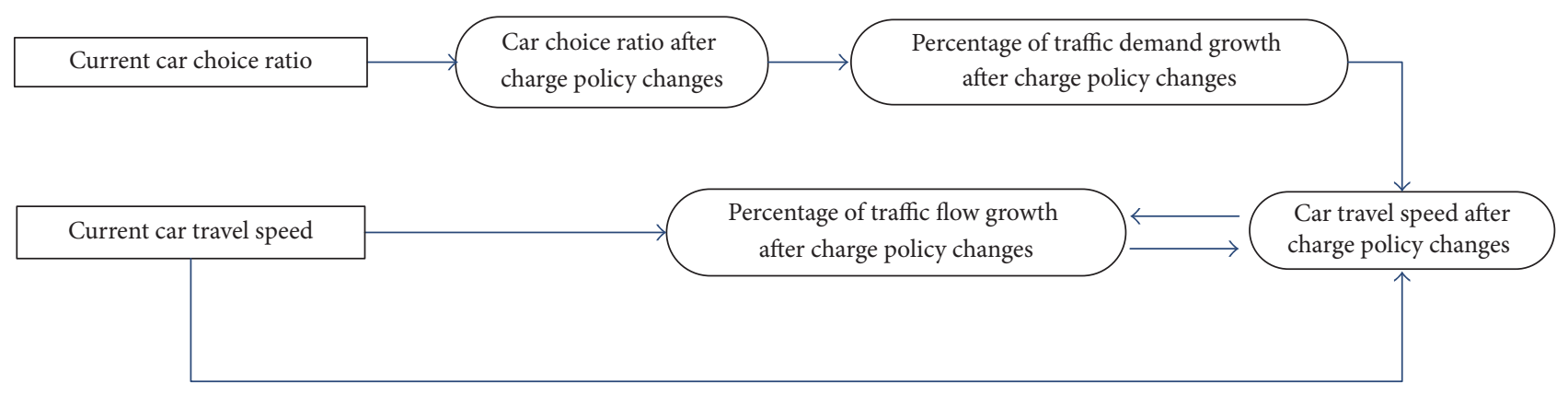

Endogenous variable
Exogenous variable

FIGURE 5: Relation between travel mode distribution and travel speed.

where $Q_{x}, N_{x}$, and $V_{x}$ are the traffic flow, total number of cars, and average travel speed, respectively, under the condition of changes in parking charges. Measured speed $V_{x}$ after changes in the policy for parking charges can be calculated as

$$
\frac{N_{x}^{\beta}\left(V_{0}-V\right)}{N^{\beta} V^{\beta}} V_{x}^{\beta+1}+V \times V_{x}-V_{0} \times V=0
$$

So, (9) is a multidegree univariate polynomial equation about $V_{x}$. If the total number of cars before and after the charge policy changes, the current travel speed, and a series parameter are determined, travel speed $V_{x}$ after the charge policy changes can be solved using the Matlab program.

(2) Effect of Parking Search Time on Traffic Congestion. When parking facilities become saturated, search circuits and cruising flows increase traffic congestion when vehicles search for parking space on the road. Assuming that parking search time is $T_{s}$ and car travel time on one trip is $T$, then the total number of cars $N_{s}$ that have been added to the number of searching cars on the road is

$$
N_{s}=N\left(1+\frac{T_{s}}{T}\right)
$$

Parking search time and the ratio of parking supply and demand have an exponential relationship [16] as shown in Figure 6.

\section{Case Analysis}

To verify the accuracy of the suggested model and to evaluate future policy, this article takes Wulin CBD in Hangzhou as the study area. The area of Wulin CBD is approximately $18.8 \mathrm{~km}^{2}$ and the population is about 0.65 million. The road networks data are the average in Wulin CBD. Data are collected from the Hangzhou Bureau of Statistics and parking survey information. Parking fee data are obtained from the Hangzhou Price Bureau.

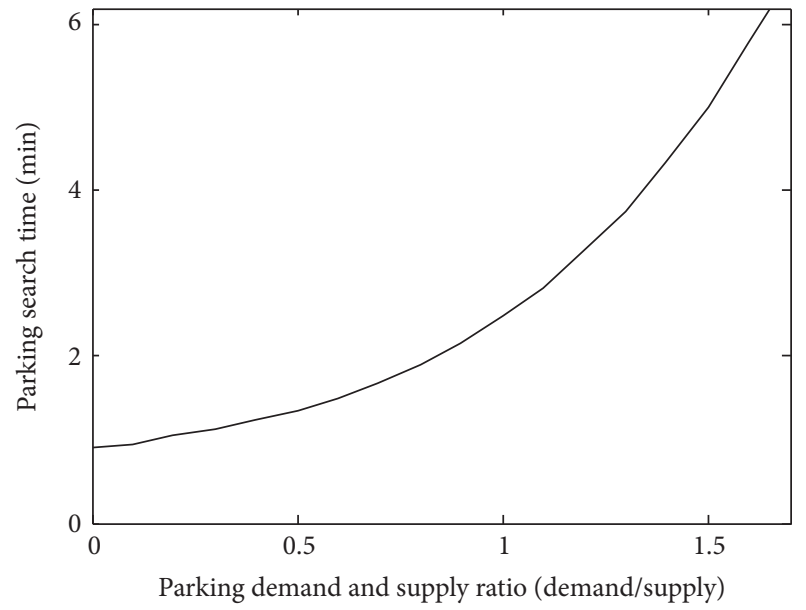

FIGURE 6: Relation between parking search time and parking demand and supply ratio.

\subsection{Parameter Calibration}

(1) Travel Cost of Different Travel Modes. The average wage of a Hangzhou on-the-job worker in 2014 is 9794.5 \$, the hourly wage is $4.63 \$ / h$, and the corresponding time value is $1.41 \$ / \mathrm{h}$. The travel cost of three types of travel mode is calculated in Table 1.

$v$ is the average speed in the area $(\mathrm{km} / \mathrm{h}), T$ is the total time for this travel mode on one trip (h), $P_{c}$ is the parking fee $(\$ / \mathrm{h}), T_{p}$ is the total parking time on one trip $(\mathrm{h})$, and $T_{s}$ is the parking search time (h). \lceil\rceil is always rounded down to the nearest whole unit.

(2) Parameters of Travel Mode Choice. According to some relevant documents from the Hangzhou Price Bureau, parking fee in the core zone was $0.92 \$ / \mathrm{h}$ before the new parking policy took effect. After the implementation of new parking policy, parking fee for the first hour has increased to $1.54 \$$ and the follow-up time is $1.95 \$ / \mathrm{h}$. According to the data of the Hangzhou Comprehensive Transportation Research Center, the average travel distance in Hangzhou is $8.19 \mathrm{~km}$, average parking time is $2.17 \mathrm{~h}$, average travel speed in the core zone 
TABLE 1: Travel cost of all types of travel mode.

\begin{tabular}{lc}
\hline Travel mode & Travel cost (dollars) \\
\hline \multirow{2}{*}{ Car } & Off-peak: $\left(5.143-0.077 v+0.001 v^{2}\right) 1.01 T+P_{c} T_{p}+1.41 T+0.25 T+2.12 T_{s}$ \\
& Peak: $\left(5.917-0.127 v+0.002 v^{2}\right) 1.01 T+P_{c} T_{p}+1.41 T+0.25 T+2.12 T_{s}$ \\
\hline \multirow{2}{*}{ Bus } & Fuel cost + parking cost + travel time cost + reliability cost + parking search time cost \\
\hline \multirow{2}{*}{ Taxi } & Off-peak: $0.30+1.41 T+2.12 \times(7.3+5.9) / 60+2.12 \times 10.4 / 60+0.33 T+1.01 T$ \\
& Peak: $0.30+1.41 T+2.12 \times(7.3+5.9) / 60+2.12 \times 10.4 / 60+0.33 T+0.91 T$ \\
& Bus fare + travel time cost + walking cost + waiting time cost + comfort cost + reliability cost \\
\hline
\end{tabular}

TABLE 2: Distribution of extra and commute trips.

\begin{tabular}{lccc}
\hline & Car & Bus & Taxi \\
\hline Extra trip proportion & $26.44 \%$ & $19.10 \%$ & $1.26 \%$ \\
Commute trip proportion & $11.01 \%$ & $21.53 \%$ & $1.05 \%$ \\
\hline
\end{tabular}

before the new policy implementation is $18.83 \mathrm{~km} / \mathrm{h}$, parking demand and supply ratio is 1.05 , and extra trip proportion is $20 \%$. The distribution of the different travel mode choices is shown in Table 2.

In order to investigate the sensitivity to parking charge increasing of travelers, a questionnaire focused on extra parking behavior is designed in this study. We used the investigation method combining RP survey and SP survey [28]. RP survey mainly contains the traveler's travel choice, travel distance, reasons for parking choice, and so forth. And SP survey investigates the preferences of travelers under the hypothesis that parking charge increases in different levels.

The survey issued a total of 350 questionnaires; for the reason that this study focused on extra parking behavior, a total of 200 valid samples were recovered. Based on the 200 questionnaires obtained from the survey on parking behavior, $10.5 \%$ of vehicle drivers choose other ways to travel when the parking fee increased to $2.31 \mathrm{\$} / \mathrm{h}$, and the percentage increases to $22.5 \%$ when the parking fee increased to $3.08 \$ / \mathrm{h}$

Through the travel cost estimation subsystem, we can obtain that the car travel cost is $7.50 \$$ at peak hours when the parking fee in the core zone was $0.92 \$ / \mathrm{h}$, and it rises to $9.20 \$$ after the implementation of the new parking policy. Also, if the parking fee increases to $2.31 \$ / \mathrm{h}$, the car travel cost is $10.51 \$$.

Using the logit model in the travel mode choice subsystem, we can obtain the following two equations:

$$
\begin{aligned}
\frac{\exp \left(7.5 \eta_{c}\right)}{\exp \left(7.5 \eta_{c}+C\right)} & =26.44 \%, \\
\frac{\exp \left(10.51 \eta_{c}\right) / \exp \left(10.51 \eta_{c}+C\right)}{\exp \left(9.2 \eta_{c}\right) / \exp \left(9.2 \eta_{c}+C\right)} & =1-10.5 \%,
\end{aligned}
$$

where $C$ is a constant which represents the travel costs of other travel modes except cars, such as bus and taxi. By calculating (11), we can obtain that $\eta_{c}=-0.1061$ and $C=$ 1.2445. So, car travel cost influence coefficient is -0.1061 . Similarly, the coefficient of other travel costs is calculated in Table 3.
TABLE 3: Coefficient of travel cost of all types of travel mode.

\begin{tabular}{lccc}
\hline & Car & Bus & Taxi \\
\hline Travel cost influence coefficient & -0.1061 & -0.4921 & -0.1133 \\
Constant term & & 0.8787 & \\
\hline
\end{tabular}

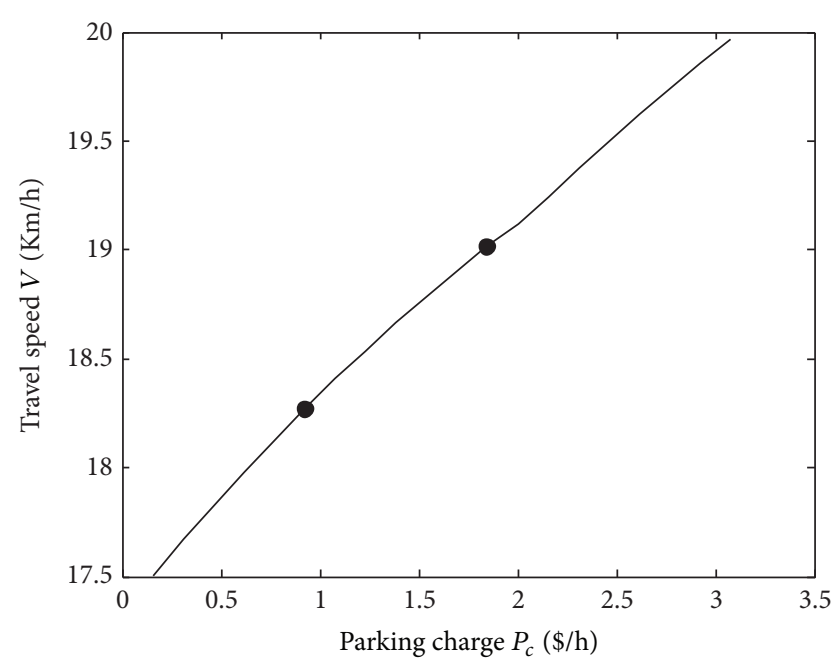

FIGURE 7: Relation between parking charge and travel speed.

3.2. Model Validation. The new parking policy in Hangzhou was implemented on 25 August 2014. The road network data before and after the policy implementation can be used to detect the accuracy of the suggested model. According to the data from the Hangzhou Comprehensive Transportation Research Center, the average travel speed in the core zone before the implementation of the new policy is $18.83 \mathrm{~km} / \mathrm{h}$ (based on three consecutive Tuesday mornings peak data in May 2014). The average speed after the implementation of the new policy is $19.16 \mathrm{~km} / \mathrm{h}$ (based on three consecutive Tuesday mornings peak data in October 2014). To calibrate the parameters $\alpha$ and $\beta$ in the BPR function, the measured traffic flow data in the study area are used to fit the BPR function. After function fitting, the parameters $\alpha$ and $\beta$ are chosen as 0.5 and 4.0 , respectively.

The current travel speed in the Hangzhou core zone was used as basic data. The relation between parking charge and travel speed is simulated in Figure 7. 
TABLE 4: Simulation of effect of different policies.

\begin{tabular}{lcccc}
\hline Parking policies & Current situation & $\begin{array}{c}\text { Decreasing supply }(-20 \%) \\
\text { Charge unchanged }\end{array}$ & $\begin{array}{c}\text { Increasing supply (+20\%) } \\
\text { Charge unchanged }\end{array}$ & $\begin{array}{c}\text { Supply unchanged } \\
\text { Increasing charge to } \\
3.07 \text { \$h }\end{array}$ \\
\hline Travel speed $(\mathrm{km} / \mathrm{h})$ & 19.16 & 18.80 & 19.54 & 20.31 \\
Parking search time $(\mathrm{min})$ & 2.66 & 3.59 & 2.15 & 1.99 \\
\hline
\end{tabular}

According to the model, the average travel speed before the implementation of the new policy is $18.39 \mathrm{~km} / \mathrm{h}$. Backstepping was performed and showed a relative error of $2.2 \%$ compared with the actual travel speed.

\subsection{Future Parking Policy Simulation and Discussion. Policy} simulation predicts the possible influence of the parking policy on the road network after the implementation of the new policy according to the actual situation and development direction of Hangzhou. According to the current version, the total number of vehicles in Hangzhou will continue to increase for a long period in the future. Therefore, parking policy in the core zone should focus on improving the level of network service. Increasing the parking supply or lowering the parking fees increases parking demand, thus increasing the congestion degree in the core area. On the other hand, increasing the parking supply will reduce parking search time on the road. So the effect on the level of network service remains uncertain.

Parking policy can be divided into three categories: decreasing supply, increasing supply, and increasing parking charge. The effects of different policies after the policy implementation are evaluated though travel speed. The simulation travel speed under several specific policies is shown in Table 4, and the relationship between parking charge, parking supply, and travel speed is illustrated in Figure 8.

According to the results of the simulation, we can see the following from the table and the figure:

(1) Decreasing supply on the basis of current situation will reduce the number of vehicles in core area, but the parking problems will be more prominent. Also, parking search time on the street will be longer which will increase congestion and the average travel speed will decline.

(2) Increasing supply on the basis of current situation will attract more vehicles in core area, but for the reason of its convenience of parking and less parking search time, the network average travel speed has a small rise. However, this policy is difficult to achieve for the land use restrictions in core zone.

(3) When parking supply continues to increase, the traffic system travel speed will show a trend of slow decline after reaching an extreme value. This result is not difficult to imagine for the attraction of a large number of vehicles into the core area due to the less travel cost.

(4) Changes in parking fees allow the emphasis on the use of pricing which is critical in obtaining the best

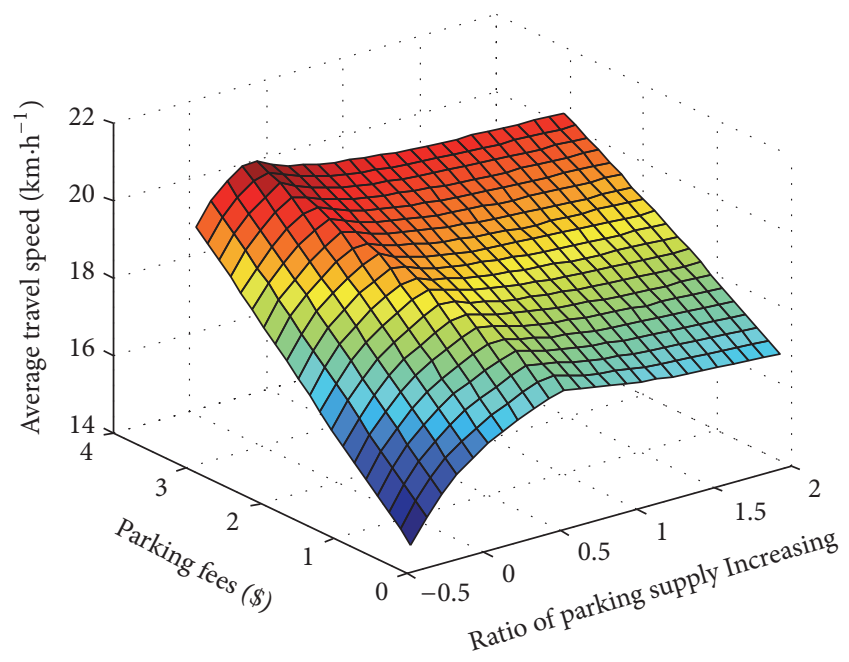

FIGURE 8: The relation between parking charge, parking supply, and travel speed.

performance of the traffic system. In this model, the losses in average travel speed incurred by not applying a price will reach $16 \%$. A curious outcome is that the performance achieved is better with very high prices than with a zero price alternative.

(5) An interesting finding is that, under certain parking supply conditions, there is an interval of possible pricing at which the travel speed reaches a level that is fairly stable. In the traffic system well illustrated by this model, politicians would rather keep prices at high levels in order to optimize the city traffic system service level, but under public acceptability constraints they would rather keep prices at low levels of this interval, which may ignore the other possible targets, such as reducing air pollution or releasing of public space.

\section{Conclusion}

With the emergence of new technological possibilities and political considerations, the present use of parking-based policy instruments as a response to urban problems of road congestion has been paid more and more attention. Because the parking policy is an instrument to manage the urban road demand, it is necessary to consider the aggregate traffic flow behavior. However, due to the complexity of the traffic system, it is difficult to directly estimate the effect of the implementation of the parking policy. Therefore, it is 
necessary to make use of the method of system dynamics to simulate and predict the effect of policy implementation.

This paper aims to build a simulation model that can be used to evaluate the effects of different parking policies. This article verifies the model using the basic data of a road network before and after implementation of parking policy in Hangzhou. This study simulates the effects of different parking policies on the simulation results obtained with different objectives. The maximum average speed can be obtained with a price for parking. Decreasing supply on the basis of current situation will increase the parking search time, which will cause traffic congestion. And increasing parking supply will produce limited benefits.

This study focuses on the average travel speed in a certain area and does not forecast some parameters of a specific road. The case of application parameterized and successfully calibrated the model with available local data, but the efficiency of parking supply policy has not been confirmed by the actual data, and the parameters affecting the parking search time should be more specific in future studies.

\section{Conflicts of Interest}

The authors declare that they have no conflicts of interest.

\section{Acknowledgments}

The current work is supported by the Zhejiang Provincial Natural Science Foundation of China (no. LY15E080008), the National Natural Science Foundation of China (no. 50908205), and the Hangzhou Science and Technology Development Program (no. 20142013A57).

\section{References}

[1] J. C. Falcocchio and H. S. Levinson, Road Traffic Congestion: a Concise Guide, vol. 7, Springer Tracts on Transportation and Traffic, 2015.

[2] B. P. Feeney, "A Review of the impact of parking policy measures on travel demand," Transportation Planning \& Technology, vol. 13, no. 4, pp. 229-244, 1989.

[3] J. M. Morrall and D. Bolger, "The relationship between downtown parking supply and transit use," ITE Journal, vol. 4, pp. 32-36, 1996.

[4] Y. Shiftan and R. Burd-Eden, Modeling the Response to Parking Policy, 36-38, July 2000.

[5] S. Hess and J. Polak, "Mixed logit estimation of parking type choice," in Proceedings of the 83rd Annual Meeting of the Transportation Research Board, Washington DC, Wash, USA, 2004.

[6] J. Simićević, S. Vukanović, and N. Milosavljević, "The effect of parking charges and time limit to car usage and parking behaviour," Transport Policy, vol. 30, pp. 125-131, 2013.

[7] G. Albert and D. Mahalel, "Congestion tolls and parking fees: A comparison of the potential effect on travel behavior," Transport Policy, vol. 13, no. 6, pp. 496-502, 2006.

[8] G. Marsden, "The evidence base for parking policies-a review," Transport Policy, vol. 13, no. 6, pp. 447-457, 2006.
[9] R. Arnott and J. Rowse, "Modeling parking," Journal of Urban Economics, vol. 45, no. 1, pp. 97-124, 1999.

[10] W. B. Cutter and S. F. Franco, "Do parking requirements significantly increase the area dedicated to parking? A test of the effect of parking requirements values in Los Angeles County," Transportation Research Part A: Policy and Practice, vol. 46, no. 6, pp. 901-925, 2012.

[11] Z. Qian and R. Rajagopal, "Optimal dynamic parking pricing for morning commute considering expected cruising time," Transportation Research Part C: Emerging Technologies, vol. 48, pp. 468-490, 2014.

[12] A. Millard-Ball, R. Weinberger, and J. Hampshire, "Is the curb $80 \%$ full or $20 \%$ empty? Assessing the efficacy of San Francisco's parking experiment," in Proceedings of the 92nd Annual Meeting on Transportation Research Board, pp. 76-92, 2013.

[13] D. C. Shoup, “Cruising for parking," Transport Policy, vol. 13, no. 6, pp. 479-486, 2006.

[14] S. Dou, X. Li et al., "Study on logistics industry development policy based on system dynamics: a case study of Beijing," Journal of Industrial Engineering \& Management, vol. 9, no. 7, pp. 305-315, 2011.

[15] A. K. Abbas and M. G. H. Bell, "System dynamics applicability to transportation modeling," Transportation Research Part A: Policy and Practice, vol. 28, no. 5, pp. 373-390, 1994.

[16] J. P. R. Bernardino and M. V. D. Hoofd, "Parking policy and urban mobility level of service-system dynamics as a modelling tool for decision making," European Journal of Transport and Infrastructure Research, vol. 13, no. 3, pp. 239-258, 2013.

[17] E. T. Keeler and K. Small, The Full Costs of Urban Transport: Part III. Automobile Costs and Final Intermodal Cost Comparisons, IURD Monograph Series, Institute of Urban and Regional Development, University of California, Berkeley, 1975.

[18] R. Barff, D. Mackay, and R. W. Olshavsky, "A Selective review of travel-mode choice models," Journal of Consumer Research, vol. 8, no. 4, pp. 370-380, 1982.

[19] Y. Ying, Study on the Method of Travel Mode Chaining Cost, Zhejiang University, Hangzhou, China, 2015.

[20] R. G. Mcgillivray, "Demand and choice models of modal split," Journal of Transport Economics \& Policy, vol. 4, no. 2, pp. 192207, 1970.

[21] M. F. Wigner, Disaggregated modal-choice models of downtown trips in the Chicago region, 1973.

[22] H. D. Pickrell and D. C. Shoup, "Employer-subsidized parking and work-trip mode choice [J]," Transportation Research Record, 1980.

[23] F. S. Koppelman, C. R. Bhat, and J. L. Schofer, "Market research evaluation of actions to reduce suburban traffic congestion: Commuter travel behavior and response to demand reduction actions," Transportation Research Part A, vol. 27, no. 5, pp. 383393, 1993.

[24] C. E. Khin, K. Sakamoto, and H. Kubota, "Parking policy and its effects in traffic flow in CBD areas in developing countries," in Proceedings of the 9th World Conference on Transport Research, 2001.

[25] M. K. Gwilliam, “The Value of Time in Economic Evaluation of Transport Projects, Lessons from Recent Research," Proceedings of the Value of Time Seminar, vol. 26, no. 3, pp. 674-677, 1997.

[26] W. Dian-hai, Y. Ying, Z. Wen-tao, and Q. Hong-sheng, "Estimating crowding costs in bus based on contingent valuation method," Journal of Jilin University Engineering and Technology Edition. 
[27] K. Hai-lin, W. Jin-song, and W. Yun-peng, "Vehicle fuel consumption model based on urban road operations," Journal of Jilin University (Engineering and Technology Edition), vol. 39, no. 5, pp. 1146-1150, 2009.

[28] Q. Y. Fang, T. Y. Chang, and Z. R. Peng, SP/RP SurveyBased Study on Parking Lot Planning and Pricing Policies, Transportation Standardization, 2013. 


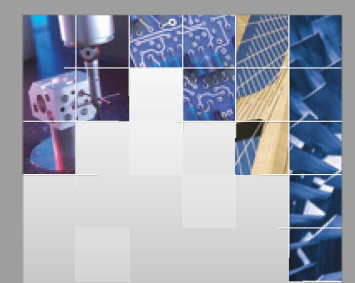

\section{Enfincering}
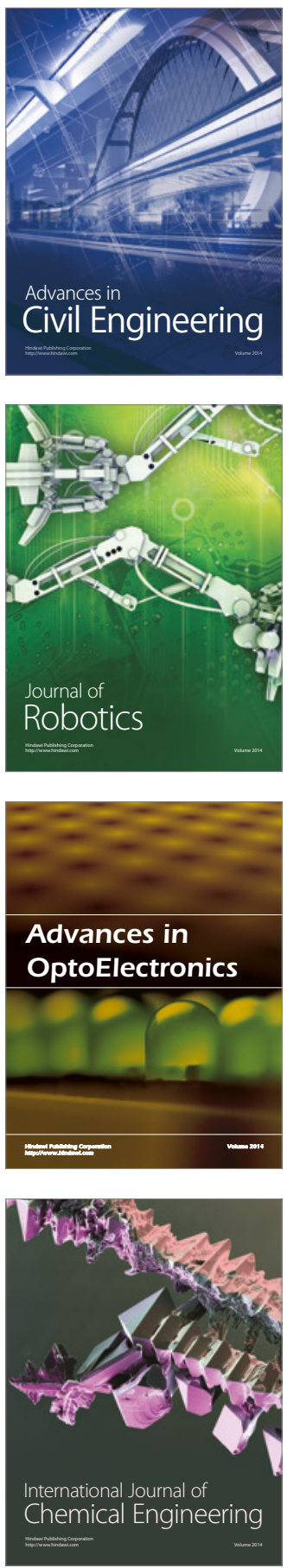

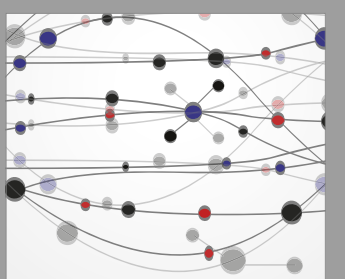

The Scientific World Journal

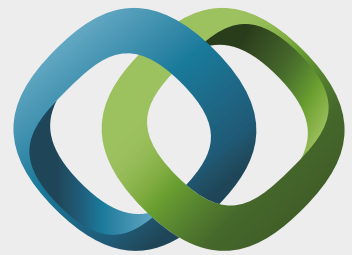

\section{Hindawi}

Submit your manuscripts at

https://www.hindawi.com
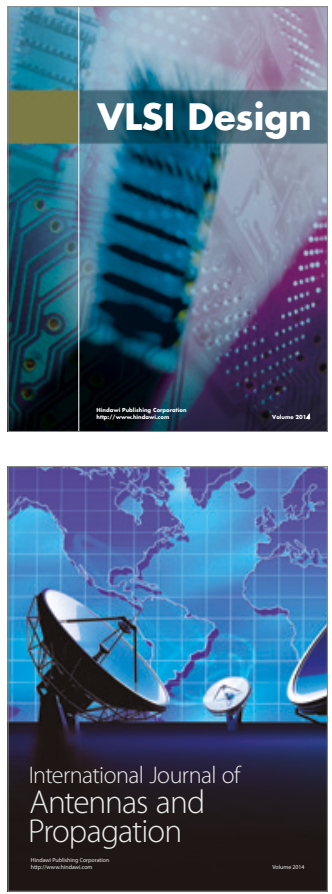

\section{Rotating}

Machinery
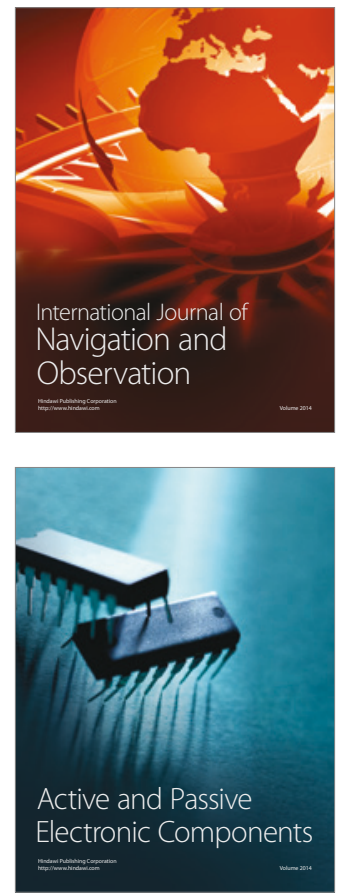
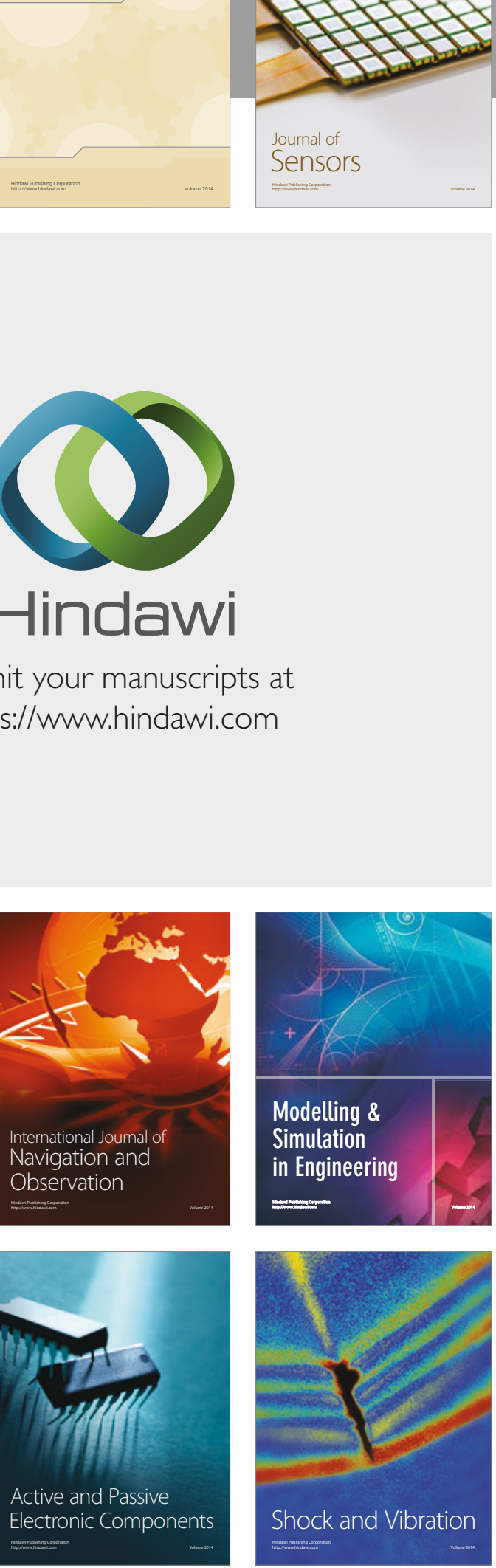
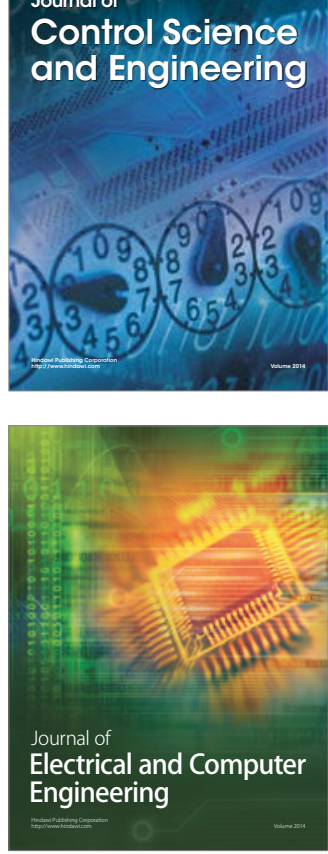

Distributed

Journal of

Control Science

and Engineering
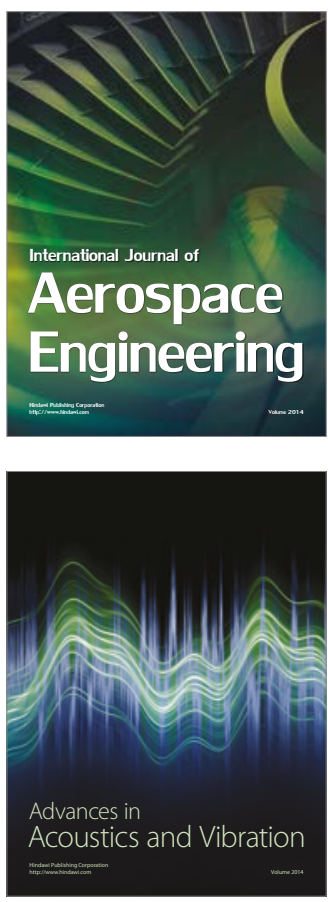

Sensor Networks 